\title{
Eutanásia: pelas veredas da morte e da autonomia ${ }^{\star}$
}

\author{
Euthanasia: along the road of death and autonomy
}

Rodrigo Siqueira-Batista 1

Fermin Roland Schramm 2

* Trabalho realizado no Departamento de Ciências Sociais, Escola Nacional de Saúde Pública, Fundação Oswaldo Cruz e no Núcleo de Estudos em Filosofia e Saúde, Fundação Educacional Serra dos Órgãos (Nefisa-Feso). 1 Departamento de Ciências Sociais, ENSP/Fiocruz e Núcleo de Estudos em Filosofia e Saúde, Fundação Educacional Serra dos Órgãos (Nefisa-Feso). Av. Alberto Torres 111, Alto, 25964-000, Teresópolis RJ. anaximandro@hotmail.com 2 Departamento de Ciências Sociais, ENSP/Fiocruz.
Abstract This article sets out from the question: Would a definition of the concept of death, which could be considered trustworthy and therefore consensual, be considered crucial for the moral legitimacy of euthanasia? It seeks to address this quest expounding on the problems involving the attempts of a scientific definition of death when this definition is necessary for ethical consideration related to the end of life, as it is the case in euthanasia or assisted suicide. The argumentation is based on Hume's Law which prohibits "values" to interfere with "facts" and on the evolutionary concept of scientific ideas arising from Kant's famous distinction between the unknowable thing-in itself and the knowable thing-as-itappears, which gives rise to a methodological conclusion: the incommensurability between the order of facts and the order of values, meaning that a definition of an event/process such as death can only be compared to the order of facts, and the same applies to values. Furthermore, it seeks to delimit an alternative field for this discussion, which notwithstanding its limitations is quite useful for the bioethical argumentation: the principle of autonomy intrinsic to the order of values. Key words Bioethics, Euthanasia, Death, Autonomy
Resumo $O$ artigo parte da pergunta: o estabelecimento de um conceito de morte, que possa ser considerado fidedigno e, portanto, consensual, seria premissa crucial para a legitimação moral da eutanásia? Procura responder, expondo os problemas que cercam as tentativas de uma definiçãocientífica - de morte, no momento em que se tenta utilizá-la na tomada de decisões - éticas - em relação ao fim da vida, como no caso da eutanásia e do suicídio assistido. Baseia a argumentação na Lei de Hume, que proíbe a inferência de "valores" a partir de "fatos", e na concepção evolutiva de conceitos científicos, decorrente da distinção, de origem kantiana, entre o que é (coisa em si ou númeno) e o que é conhecido (ou fenômeno), $e$ cuja principal conclusão, de tipo metodológico, é a incomensurabilidade entre a ordem dos fatos e dos valores, ou seja, uma definição de um evento/processo como a morte só pode ser comparada com outra definição pertencente à mesma ordem, o mesmo aplicável aos valores. De outro modo, o manuscrito procura delimitar um referencial alternativo para o debate, que, apesar de suas limitações, se mostra bastante útil para a argumentação bioética: o princípio da autonomia, intrínseco à ordem dos valores.

Palavras-chave Bioética, Eutanásia, Morte, Autonomia 


\section{Introdução}

"Oh! pequena nuvem", disse a virgem,

"peço-te que me digas

Por que não te queixas quando, num instante, desapareces;

Então te procuramos, mas não

encontramos. Ah! Thel se parece contigo:

Dissipo-me: contudo, queixo-me,

e ninguém ouve minha voz."

William Blake

A morte é a indelével certeza da condição humana, embora quase sempre recalcada, constituindo intrínseca peculiaridade do Homo sapiens sapiens, o único vivente que tem a consciência da sua própria finitude (Freud, 1974). Sob uma perspectiva mais abrangente, seria diante da morte que o ser humano, tão ávido na busca de certezas, poderia amainar o seu desconforto e sua perplexidade diante de um real com possibilidades tão remotas de verdade (Detienne, 1988; Siqueira-Batista, 2003) - afinal, o êxito letal é a última e incontornável fronteira, geralmente pensada em relação ao outro e quase nunca em relação a si (Hegel, 1992).

Sem embargo, a morte está longe de ser um tema de fácil abordagem e manejo, sobretudo nos dias atuais - mas não somente hoje (Elias, 2001). Muitas vezes tem sido vedada, nos mais distintos ambientes e lugares, a questão da morte como assunto de debate, tornando o mote um genuíno tabu, em relação ao qual se adota a esquiva como atitude principal. A repulsa ao tema parece ter como um dos seus liames precípuos o sentimento de angústia e desamparo diante da idéia de finitude e do incognoscível (Schramm, 2002a). Ademais, a dimensão elegíaca da perda quase invariavelmente atrelada ao "ocaso" é também partícipe dessa intrincada textura de resistência à idéia da morte. Esta, como evento em si, não é o único problema. Não se pode perder de vista que a morte está geralmente relacionada, em muitas circunstâncias, ao sofrimento de uma doença grave ou mitigante - desfecho nefasto desse processo - ou à crueza de um acidente ou de outra causa violenta de fenecer, que ceifa a vida nos melhores dias (Siqueira-Batista, 2001). Em ambas as situações, a supressão do bem maior da vida, tanto de forma insidiosa, quanto de forma abrupta, possibilita a adoção de uma postura reflexiva, com revisão de conceitos e paradigmas por aqueles que experimentam a proximidade da morte - quer familiares, quer profissionais.

$\mathrm{Na}$ esteira dos problemas evocados pelo passamento está a questão do processo de morrer, completamente imbricado em aspectos como sofrimento e qualidade (ou precariedade) de vida (Pessini, 2001). Em uma das possíveis confluências da finitude com as questões levantadas pela tecnociência - avanços nas técnicas de manutenção da vida e prolongamento da sobrevida - está todo o debate sobre a eutanásia, a distanásia e o suicídio assistido, o que parece exigir a compreensão do fenômeno próprio representado pela morte, para uma delimitação mais adequada do problema, tanto em termos individuais, quanto coletivos. Com efeito, o progressivo envelhecimento da população - como o observado no Brasil - permite que um maior contingente de pessoas chegue à senectude, tornando-se mais suscetível às moléstias crônicas e degenerativas - como os cânceres - e, por conseguinte, a um processo de morrer mais "prolongado" e sujeito ao sofrimento. Esse panorama se traduz em importantes problemas na área de saúde pública, como aqueles relativos ao uso de recursos para o tratamento desses enfermos, e a possibilidade de que um maior número de pessoas seja excluído da adequada assistência à saúde, nesse momento tão crítico - a proximidade da morte. Assim, percebe-se que o debate sobre a bioética do fim da vida, longe de ser uma questão relativa ao indivíduo - aquele que morre -, constitui um autêntico problema de saúde coletiva.

Destarte a ponderação, não se torna imediatamente claro que o conceito de morte seja capaz de fundamentar - e legitimar - a eutanásia e o suicídio assistido, crítica esta delineada por alguns autores (Schramm, 2001). Ao contrário, as incertezas em relação à possibilidade de uma definição inequívoca da morte tem sido motivo para um vasto manancial de discussões acerca da licitude de se prescrever (ou permitir) a eutanásia. Na legislação brasileira, com efeito, a eutanásia é vista como homicídio, com base em uma definição de óbito, qualquer que seja ela. Isto traz um relevante problema no que se refere, por exemplo, à questão dos transplantes de órgãos, nos quais o diagnóstico de morte encefálica é o critério para que o "morto" seja submetido a uma cirurgia para retirada dos órgãos.

Baseado nessas premissas, pretende-se abordar duas perguntas consideradas essenciais para o assunto em pauta: (1) Seria possível utili- 
zar algum conceito de morte como sustentáculo para a argumentação ética acerca da eutanásia? (2) Em caso negativo, haveria outro referencial teórico substitutivo capaz de fornecer elementos à legitimidade moral da eutanásia e, se sim, a que ordem pertenceria? Buscar a resposta para essas questões, partindo-se de uma breve apresentação do problema representado pelo fim da vida na prática médica, é o escopo do presente artigo.

\section{O médico e o fim da vida}

A medicina é uma das práticas humanas que colocam o profissional diante de seus mais íntimos conflitos, ou seja, em poucas atividades o indivíduo encontra-se tão incisivamente sujeito às pressões, de várias ordens, e ao desgaste profissional (Machado, 1997). A peculiar face de agir, na maior parte das vezes, nas condições em que pulula a dor - momento em que se rompe o equilíbrio próprio à saúde -, faz do médico um profissional permanentemente confrontado com as indagações evocadas pelo sofrimento, em suas mais diferentes facetas (Machado, 1997).

Habitualmente não se pode sair impune de um contexto muitas vezes caracterizável como confronto direto com o sofrimento, o qual tem como perene pano de fundo o óbito. A presença da morte - aquela que, segundo concepção vigente, precisa ser enfrentada pelo médico instaura no exercício profissional um alto grau de compromisso para com o enfermo que caminha para a restituição da saúde ou ao êxito letal. Essa disposição pessoal de enfrentamento da morte por parte do médico - aliada à empatia para com o paciente que deve se confrontar com ela - é originada ainda nos primeiros anos da graduação (Siqueira-Batista \& Siqueira-Batista, 2002). Desde cedo, o estudante de medicina é moldado para ver a morte como "o maior dos adversários”, o qual deverá ser sempre combatido e, se possível, vencido graças à melhor ciência, ou competência, disponível. Essa caracterização de médico como aquele que vence a morte já é perceptível na própria narrativa mitopoética, podendo ser lembrado o mito de Asclépio (Cedrola et al., 2003), o deus grego filho de Apolo que, em seu aprendizado com o centauro Quíron, teria adquirido a habilidade de ressuscitar os mortos:

Na verdade, [Asclépio] recebera de Atena o sangue que escorrera das veias da Górgona; en- quanto as veias do lado esquerdo tinham espalhado um veneno violento, o sangue do lado direito era benéfico e Asclépio sabia utilizá-lo para dar vida aos mortos. O número de pessoas que ele ressuscitou desse modo é considerável. Entre elas conta-se Licurgo, Glauco (filho de Minos) e Hipólito (filho de Teseu) (Grimal, 1997).

É deveras interessante perceber, neste excerto, o desejo implícito no imaginário médico de vencer a morte, muitas vezes tão inerente à postura daqueles que praticam a medicina, mesmo nos dias de hoje, em conformidade ao relatado por Márcio P. Horta:

Quando a vida física é considerada o bem supremo e absoluto, acima da liberdade e da dignidade, o amor natural pela vida se transforma em idolatria. A medicina promove implicitamente esse culto idólatra à vida, organizando a fase terminal como uma luta a todo custo contra a morte (Horta, 1999).

Aqui é a dialética vida-morte que está presente: ou acerto ou morre o paciente! A densa noção de responsabilidade pela existência do enfermo e a permanente necessidade de decidir nos momentos cruciais são os elementos-chave dessa malha interconectada geradora de angústia (Palacios, 1993).

Deste modo, quando sobrevém o óbito, a sensação de angústia incutida pela percepção da derrota é capaz de minar, em muito, a disposição do profissional - afinal, entram em jogo a frustração e a "exposição" de uma ferida narcísica na prepotência médica (Schramm, 2002a) -, alterando substancialmente sua relação com a morte e com aqueles que se encontram em plena experiência do processo de morrer. Assim, o médico pode se tornar extremamente reticente para lidar com enfermos em tais condições, por um lado, abrindo-se a perspectiva para uma luta desenfreada e (ir)racional, com vistas à manutenção da vida a qualquer custo e sob qualquer pretexto, muitas vezes com extremo sofrimento por parte do paciente, por outro. Neste último caso, tem-se a distanásia, termo inicialmente proposto por Morcache, em 1904, no seu livro Naissance et mort, significando uma agonia prolongada que origina uma morte com sofrimento físico ou psicológico do indivíduo lúcido. O vocábulo é freqüentemente utilizado também no intuito de designar a forma de prolongar a vida de modo artificial, sem perspectiva de cura ou melhora (Pessini, 2001).

Se, por um lado, o médico pode digladiar com a morte de forma inclemente, por outro, 
abre-se a possibilidade, durante o lidar com aquele que morre, para a emergência de um desejo de tornar o passamento menos angustiante e mais digno. Subserviente à máxima de consolar sempre, um enfermo que se encontra na mais absoluta condição de penúria, já com a sua sorte selada pela doença - eventualmente com semanas ou dias de vida - acaba por estimular no profissional médico o esforço de condução com mínimo de padecimento, em condições dignas, até o desenlace final. Eis aqui o problema vital desta proposta de trabalho: a eutanásia.

\section{A eutanásia e o suicídio assistido}

O termo eutanásia é oriundo do grego, tendo por significado boa morte ou morte digna. Foi usado pela primeira vez pelo historiador latino Suetônio, no século II d.C., ao descrever a morte "suave" do imperador Augusto: A morte que o destino the concedeu foi suave, tal qual sempre desejara: pois todas as vezes que ouvia dizer que alguém morrera rápido e sem dor, desejava para si e para os seus igual eutanásia (conforme a palavra que costumava empregar) (Suetônio, 2002).

Séculos depois, Francis Bacon, em 1623, utilizou eutanásia em sua Historia vitae et mortis, como sendo o "tratamento adequado às doenças incuráveis” (apud Jiménez de Asúa, 1942).

De outro modo, o suicídio assistido ocorre quando uma pessoa solicita o auxílio de outra para morrer, caso não seja capaz de tornar fato sua disposição. Neste último caso, o enfermo está, em princípio, sempre consciente - sendo manifestada a sua opção pela morte -, enquanto na eutanásia, nem sempre o doente encontra-se cônscio - por exemplo, na situação em que um paciente terminal e em coma está sendo mantido vivo por um ventilador mecânico, o qual é desligado, ocasionando a morte.

Essa delimitação lexical está longe de ser ideal. Em verdade, há uma intensa polissemia do termo eutanásia, gerando inúmeros equívocos. Um exemplo é a confusão de conceitos como eutanásia e ortotanásia, este último termo significando a morte no seu tempo certo, sem os tratamentos desproporcionais (distanásia) e sem abreviação do processo de morrer (eutanásia) (Horta, 1999). Ademais, há interseção - e de certa forma, mescla - com conceitos tais como homicídio por piedade e suicídio, o que acaba por atribuir uma conotação pejorativa à palavra, trazendo grande prejuízo - e até precon- ceito - ao debate. Por isso a necessidade de se "limpar" um pouco mais o conceito. Atualmente a eutanásia seria $O$ emprego ou abstenção de procedimentos que permitem apressar ou provocar o óbito de um doente incurável, a fim de livrá-lo dos extremos sofrimentos que o assaltam [grifo nosso] (Lepargneur, 1999).

Apesar de não permitida na quase totalidade dos países - exceção feita à Holanda, à Suíça e à Bélgica - a eutanásia é considerada uma prática relativamente comum (Lepargneur, 1999), sobretudo a passiva - mas também a ativa, destaca Peter Singer: Cálculos aproximados [na Holanda] indicam que cerca de 2.300 mortes resultam, todos os anos, da prática desse tipo de eutanásia [ativa] (Singer, 1998).

Um estudo sobre decisões relativas ao fim da vida, realizado na Holanda em 1995, em pacientes infantis com menos de um ano, mostrou que $57 \%$ de todas as mortes foram precedidas pela decisão de retirar (ou não oferecer) o suporte de vida; em $23 \%$ dos casos foram empregados fármacos capazes de antecipar a morte, e em $8 \%$, a administração intencional de drogas letais foi instituída (Van der Heide, 1997).

A abreviação do momento da morte poderia ocorrer de distintas formas, em relação ao ato em si, de acordo com uma distinção já clássica, a saber (Neukamp, 1937):

1) eutanásia ativa, ato deliberado de provocar a morte sem sofrimento do paciente, por fins humanitários (como no caso da utilização de uma injeção letal);

2) eutanásia passiva, quando a morte ocorre por omissão em se iniciar uma ação médica que garantiria a perpetuação da sobrevida (por exemplo, deixar de se acoplar um paciente em insuficiência respiratória ao ventilador artificial);

3) eutanásia de duplo efeito, quando a morte é acelerada como conseqüência de ações médicas não visando ao êxito letal, mas sim ao alívio do sofrimento de um paciente (por exemplo, emprego de uma dose de benzodiazepínico para minimizar a ansiedade e a angústia, gerando, secundariamente, depressão respiratória e óbito).

Uma outra maneira de se classificarem as várias modalidades de eutanásia leva em conta não só as conseqüências do ato, mas também o consentimento do paciente (Martin, 1998):

1) eutanásia voluntária, a qual atende uma vontade expressa do doente - o que seria um sinônimo do suicídio assistido; 
2) eutanásia involuntária, que ocorre se o ato é realizado contra a vontade do enfermo - ou seja, sinônimo de "homicídio";

3) eutanásia não voluntária, quando a morte é levada a cabo sem que se conheça a vontade do paciente.

Estabelecida a questão semântica, complicada por diferentes terminologias, impõe-se a discussão do problema moral pertinente, ou seja, dos argumentos pró e contra a eutanásia, questão bioética que se pode chamar de controvérsia sobre a moralidade da eutanásia. Com efeito, os autores que "defendem" a prática apontam para a necessidade de que seja respeitada a liberdade de escolha do homem que padece - e que decide, como agente competente e autônomo, pôr fim aos seus dias -, além de argumentar que a eutanásia se reveste de um genuíno estofo humanitário, propiciando que se livre o enfermo de um sofrimento insuportável, encurtando uma vida considerada sem qualidade - pelo próprio paciente -, não albergando mais nenhum sentido para ser vivida. Entrementes, a despeito dessas visões, a eutanásia é uma atitude sujeita a vários questionamentos, alguns de indubitável legitimidade, como os que envolvem o princípio da sacralidade da vi$d a$ - uma das bases de sustentação para os autores que desaprovam a eutanásia. Neste caso, a vida como bem concedido pela divindade - ou pelo finalismo intrínseco da natureza - teria um estatuto sagrado, isto é, incomensurável do ponto de vista de todos os "cálculos" que possam, eventualmente, ser feitos sobre ela, não podendo ser interrompida, nem mesmo por expressa vontade de seu detentor. Outras ponderações contrárias à eutanásia incluem: 1) a potencial desconfiança - e subseqüente desgaste - na relação médico-paciente; 2 ) a possibilidade de atos não inspirados em fins altruístas, mas motivados por outras razões (por exemplo, questões de heranças, pensões, seguros de vida, e outras); 3) a ocorrência de pressão psíquica - por exemplo, o pensamento, pelo enfermo, de que sua condição é um verdadeiro "estorvo" para os familiares -, a qual poderia deixar os pacientes, cuja morte se aproxima, sem perspectiva outra que não a "eutanásia”, de fato não desejada e, portanto, de alguma forma imposta por motivos circunstanciais.

Todos os argumentos - favoráveis e contrários - são passíveis de contestações, não cabendo aqui, entretanto, que estas sejam esmiuçadas. Sem embargo, deve-se destacar o ponto considerado essencial, isto é, a questão de saber se um paciente, a princípio cognitiva e eticamente competente, sujeito a sofrimento capaz de torná-lo cioso - por motivos que lhe competem - de que sua sobrevida não é mais justificável para ser levada adiante, tem, ou não, o direito moral de escolher como terminar sua biografia, de acordo com seus princípios e valores; ou se, ao contrário, isso só pode ser o resultado de processos decisórios realizados por terceiros, supostamente mais competentes porque não instados pelas contingências; ou ainda de um acordo, a priori razoável, tendo em conta uma análise imparcial dos interesses em conflito - do paciente, dos familiares dependentes, da sociedade. A esse respeito parece realmente preferível defender o direito moral, prima facie válido, de o sujeito escolher o que considera melhor para o desfecho de sua vida, uma vez que este pode ser compreendido como um marco fundamental no exercício da autonomia pessoal e, portanto, do "empoderamento" individual, no que tange aos assim chamados " $\mathrm{di}$ reitos humanos" fundamentais.

De outro modo, o debate sobre a eutanásia remete invariavelmente ao binômio vida e morte. Neste âmbito, uma das idéias vigentes propõe que a questão seja alicerçada sobre o conceito de morte - afinal, dir-se-á que a eutanásia, em último caso, consiste em uma antecipação voluntária da morte. Assim, uma teorização acerca da morte poderia se tornar o fiel da balança para os embates travados em torno do tema. Vejam-se algumas das possíveis implicações da formulação.

\section{Os conceitos de morte}

Vida e morte podem ser apreendidas como potências ambíguas de um mesmo processo, como no dizer do filósofo Heráclito de Éfeso: $E$ como uma mesma coisa, existem em nós a vida e a morte, a vigília e o sono, a juventude e a velhice: pois estas coisas, quando mudam, são aquelas, e aquelas, quando mudam, são estas (apud Kirk et al., 1994).

Uma concepção bastante familiar permaneceu ressoando na cultura ocidental, podendo ser encontrada no pensamento filosófico moderno e contemporâneo, como em Michel de Montaigne e Karl Jaspers: Morrer é a própria condição de vossa condição; a morte é a parte integrante de vós mesmos (Montaigne, 2000). Considerando que tanto como existência quanto como consciência que temos desta própria exis- 
tência, nós somos como existência a morte (Jaspers, 1973).

$\mathrm{O}$ engendramento da morte no próprio manancial da vida se tornou um núcleo de preocupação também para Martin Heidegger, filósofo que compreendia que a vivência do processo de viver e morrer faz parte da experiência humana como Dasein (ser-aí), ou seja, de ser lançado no mundo e vulnerável no tempo, tornando-se, de alguma forma, consciente de sua condição de ser-para-a-morte (Heidegger, 1989) ou, de forma mais radical, de ser-para-o-nada, na perspectiva existencialista (Sartre, 1997). Nesses panoramas, morrer seria um dos pontos culminantes e críticos da experiência humana, prístina condição para se pensar a vida.

Sem embargo, essa caudalosa herança no Ocidente fomentou uma subversão da interseção existência-finitude, tornando a morte completamente - e tão somente - imbricada à tristeza e ao sofrimento. Desta feita, falecer significa despedir-se, deixar de fazer parte deste único mundo conhecido - ameaçador, aniquilador, "nadificador" -, afastar-se do convívio de pessoas queridas. Morrer causaria temor: é o desconhecido que está por vir.

Mas, em que consiste este momento - a morte? Em geral, quando se reflete sobre o traspasse, o que vem imediatamente ao pensamento é a morte clínica (e/ou biológica), sobretudo no âmbito do senso comum. Mas, há diferentes perspectivas para a conceituação da morte, podendo-se estabelecer:

1) a morte clínica, caracterizada por parada cardíaca (com ausência de pulso), respiratória e midríase paralítica (que surge cerca de 30 segundos após a suspensão dos batimentos cardíacos), podendo ser reversível, desde que sejam implementadas adequadas medidas de reanimação;

2) a morte biológica, que surge como uma "progressão" da morte clínica, diferindo desta por seu caráter irreversível (por exemplo, manobras adequadas de ressuscitação não regridem a midríase); caracteriza-se por "destruição" celular em todo o organismo, o que habitualmente se desenrola ao longo de 24 horas (algumas células demoram esse período para fenecer); neste caso, pode-se dizer que um evento essencial na morte celular é a ativação da enzima catepsina - a qual permanece "inerte" durante a vida - que, por sua característica proteolítica, é capaz de promover autólise da célula; mais recentemente, a lesão encefálica ir- reversível vem sendo considerada morte biológica (ver morte encefálica adiante);

3) a morte óbvia, na qual o diagnóstico é inequívoco (evidente estado de decomposição corpórea, decaptação, esfacelamento ou carbonização craniana, se há sinais como rigor mortis e livor mortis, dentre outros);

4) a morte encefálica, que é compreendida como um sinônimo para a morte biológica (resolução no 1.480/97 do Conselho Federal de Medicina), sendo caracterizada por uma série de parâmetros que atestam a lesão encefálica irreversível - situação em que todos os comandos da vida se interrompem, tornando impossível a manutenção da homeostasia corpórea (Menna Barreto, 2001) -, desde que sejam excluídos o uso de depressores do sistema nervoso central, os distúrbios metabólicos e a hipotermia, os quais podem simular tais parâmetros;

5) a morte cerebral, que não deve ser confundida com a morte encefálica, uma vez que pode ser feita a distinção entre ambas pela análise da respiração: esta função tem um "componente" voluntário e um involuntário, este último "comandando" o processo, por exemplo, durante o sono; nos casos de morte cerebral perde-se a consciência da respiração, a qual permanece funcionando de forma "automática"; se há morte encefálica o centro respiratório se torna danificado de forma irreversível, com a "vida" podendo ser mantida apenas com o emprego de instrumental tecnocientífico;

6) a morte jurídica, estipulando-se, no artigo 10 do Código Civil, que a morte termina a existência da pessoa natural; entretanto, a lei não estabelece o conceito de vida e de morte apenas se ocupando do seu momento -, cabendo à medicina, em especial à medicina legal, estabelecer os critérios válidos (Gogliano, 1998);

7) a morte psíquica, na qual a percepção psicológica da morte antecede, em um tempo variável, a morte biológica; aqui o enfermo toma consciência do escoamento progressivo e inexorável de sua vida, habitualmente após receber a notícia de ser portador de uma enfermidade incurável - por exemplo, um câncer disseminado (Kastenbaum, 1981); neste caso, a maior dificuldade do conceito de morte psíquica é a identidade estabelecida entre a morte e o processo de morrer.

Esta brevíssima explanação acerca de alguns possíveis conceitos de morte pretende trazer a dimensão do problema. Se em relação à morte biológica e encefálica pode-se questionar sobre até que ponto vai o discernimento 
das situações irreversíveis, com base em dados científicos - vide a mudança de conceito de morte cerebral para morte encefálica, e desta para morte cortical e neocortical (nestas duas últimas há comprometimento "apenas" da vida de relação) (França, 2001; Schramm, 1999) -, o que se dirá da morte psicológica, dependente da estrutura psíquica de cada indivíduo? Pode-se mencionar que esta modalidade de morte está inexoravelmente atrelada à biografia da pessoa que a experimenta, podendo ser vivenciada das maneiras mais díspares.

Ademais, há uma questão fundamental que perpassa a própria evolução da ciência: a visceral mudança sofrida pelo conceito de morte, sobretudo no século 20 , em cuja primeira metade a morte clínica era praticamente sinônimo de morte biológica. Atualmente, já no século 21, há quase que uma unificação deste último com o conceito de morte encefálica - instituído na segunda metade do século 20. Neste sentido, para Délio Kipper: a morte encefálica, na realidade, não é um modo de morrer, mas sim um diagnóstico, que é sinônimo de morte, embora existam contestações numa situação rara em que o paciente se encontre na chamada Penumbra Isquêmica Global (Kipper, 1999).

A pergunta, portanto, é: até quando perdurará esta classificação? Ou ainda, em que medida novos "conhecimentos" aplicáveis no âmbito da tecnociência não alterarão, profundamente, nos anos vindouros, a conceituação estabelecida para a morte? Em suma: haverá um tempo no qual se poderá decidir que, efetivamente, a morte aconteceu em um preciso momento?

Além das dificuldades conceituais inerentes à morte, há que se ter em mente a perspectiva do médico, profissional que irá vivenciar a morte do outro - seu paciente -, cabendo-lhe, em grande medida, a decisão, outorgada socialmente, acerca da forma de conduzir o processo. Algumas questões dessa interface - a dimensão decisória do enfermo no pleno exercício de sua autonomia - serão coligidas a seguir.

\section{Da morte "objetiva" à autonomia pessoal?}

Consoante o visto, há uma nítida fluidez no conceito de morte (Rodrigues, 1983; Ariès, 1989). Não é à toa que ele é ainda discutido e, provavelmente, para sempre discutível (Schramm, 2002b). O traspasse, no início do século 20, foi caracterizado pela cessação dos batimentos cardíacos - a morte clínica anteriormente mencionada -, enquanto, atualmente, a irreversibilidade de uma parada cardíaca, após reanimação, ou a morte encefálica podem ser considerados conceitos preponderantes de óbito. Todavia, mesmo o conceito de morte encefálica, conforme o discutido, é sujeito a controvérsias em alguns dos seus aspectos (Coimbra, 2000; Kipper, 1999), ainda mais se é levado em conta um adendo feito pelo Conselho Federal de Medicina, no intuito de estender a aplicabilidade do conceito de morte encefálica não apenas para o transplante de órgãos, abrindo a possibilidade para a suspensão da terapêutica nestes casos. Por exemplo, o Parecer no 12/98 do CFM, de 17 de junho de 1998, traz o seguinte excerto: Os critérios para verificação de morte encefálica não se aplicam apenas às situações de transplantes de órgãos. Os médicos devem comunicar aos familiares a ocorrência e o significado da morte encefálica antes da suspensão da terapêutica (CFM, 1998).

Essa extensão do conceito de morte encefálica minimizaria os riscos de abusos - reais ou supostos - referentes à possibilidade de comércio de órgãos para transplante (França, 2001).

Todo esse dilema traz à baila uma primeira conseqüência inexaurível: a vigência de um paradigma de morte é discutível o bastante para se duvidar da possibilidade de adotá-lo como fiel da balança, em um assunto tão delicado e com implicações tão vastas. Mas, por outro lado, a não referência a um paradigma pode originar conseqüências inaceitáveis para a prática clínica. Assim, exercitando a reflexão, ainda que se pudesse caracterizar de forma inequívoca em que consiste a morte - o que está longe de ser uma possibilidade vislumbrada (Kipper, 1999; Schramm, 2002b) -, o cerne do problema aí não residiria. E aqui se pode apelar ao "velho" Epicuro, que em suas preleções denunciava claramente que: Enquanto vivemos, a morte não existe; quando a morte passa a existir, nós já não existimos (apud Luce, 1994).

Se é conceituado que um indivíduo está morto, não há mais espaço para se discutir a eutanásia, uma vez que já se estabeleceu o ocaso. A questão está assim colocada: há um evento, um fato inexorável, capaz de pôr em xeque o próprio pensamento - partindo-se do pressuposto, como queriam os epicuristas, de que há cessação do mesmo após o derradeiro momento -, ou seja, a morte. Por seu turno, este momento não surge ex nihilo nihil, mas sim como des- 
fecho de um devir: o processo de morrer. E aqui está um segundo grande "tendão de Aquiles": não é a morte o que realmente importa, mas sim o seu processo, a certeza de que a vida se enveredou por um "caminho" sem volta, o qual desembocará no Hades! E, se já há enorme dificuldade em se estabelecer, de fato, o momento da morte, o que se dirá do processo de morrer, que, por definição, não pode ser pensado como "momento"? Será a ciência contemporânea capaz de delimitar com precisão, isto é, "objetivamente", a entrada neste caminho? $\mathrm{Ou}$, ao contrário, a consciência "subjetiva" de que a própria morte está em curso referir-se-á a instância psíquica e/ou filosófica?

Posto isto, parece claro que não se pode tentar fundamentar o debate ético acerca da eutanásia em um estatuto presumivelmente científico - quiçá epistemologicamente consensual - como o conceito de morte, o que parece levar a uma primeira, talvez simplória, conclusão: o ocaso, como evento, não é a questão central para se lidar moralmente com a eutanásia, mas, sim, o seu processo, o qual tem um âmago genuinamente filosófico: eutanásia e suicídio se relacionam intimamente com o sentido profundo da existência e constituem um problema essencialmente filosófico, não científico (Schramm, 2001).

Delineadas, de forma bastante introdutória, as dificuldades para se entabular uma discussão ética sobre a eutanásia com base em um conceito de morte que se presume cientificamente "objetivo" ou fidedigno - para o paradigma dominante -, resta a pergunta genuinamente ética, acerca da existência de um referencial, intrínseco à própria filosofia moral, capaz de ocupar esse possível vácuo epistemológico deixado pelas incertezas acerca da morte. Uma das possíveis respostas dadas a esta indagação passaria pela idéia, interna ao campo da ética e da longa tradição das ciências humanas e sociais - ou Geisteswissenschaften -, de autonomia pessoal, a qual permitiria, em princípio, afirmar que: Em tal sentido, pode-se dizer que, em caso de conflito de interesses e de direitos, o direito da autodeterminação tem uma prioridade léxica sobre os demais direitos no contexto de decisões referentes à vida e à morte de seu titular, quer dizer, a pessoa em princípio é mais qualificada para avaliar e decidir o rumo de sua vida [o grifo é do original] (Schramm, 2001).

De fato, o termo autonomia é originado, historicamente, no seio da democracia grega para indicar as formas de governo autárquicas, isto é, a pólis; posteriormente, a partir da modernidade, o conceito de autonomia passa a se aplicar ao indivíduo, chegando a uma formulação moral sistemática com a Fundamentação da Metafísica dos Costumes de Immanuel Kant. Mas, apesar de a idéia de autonomia estar centrada no conceito de indivíduo - um necessário "produto" da modernidade burguesa e protestante (Weber, 1973) -, pode-se buscar, igualmente, antecedentes na Antigüidade, por exemplo, na ética estóica: [Os estóicos] consideravam o suicídio a afirmação suprema da liberdade individual e pensavam que o homem como um agente moral devia ser livre para escolher a morte em vez da vida [o grifo é nosso] (apud Luce, 1994).

Desse modo, argumentos a favor da eutanásia podem ser arrolados a partir de um estofo primevo - fundado na própria tradição filosófica grega preocupada em estabelecer uma autarquia do perguntar, com relação à narração mitopoética -, encarnado no princípio da autonomia, segundo o qual cada indivíduo tem o direito de dispor de sua vida da maneira que melhor lhe aprouver, optando pela morte no exaurir de suas forças, ou seja, quando sua própria existência se tornar subjetivamente insuportável, de tal sorte que: [O interesse do indivíduo em morrer] se deve a uma razão aparentemente simples, defendida pela bioética laica e segundo a qual se se aceita que existe uma prioridade da qualidade de vida sobre a vida em si, se deve admitir também que, prima facie, o mais competente para decidir qual é a melhor qualidade de sua vida é o próprio titular [o grifo é nosso] (Schramm, 2001).

Se são deixadas de lado - provisoriamente? - as pretensões "objetivistas" sobre o que, de fato, a episteme (referente aos fatos naturais) não pode responder - porque não lhe cabe dizer o que, na "solidão" do experienciar a finitude do processo viver/morrer (Elias, 2001), cada um vivencia - parece que o fundamento, se é que isso possa existir, deverá ser encontrado em um âmbito diferente daquele da ciência. Se isto que está sendo questionado for pertinente, se estaria diante de uma radical guinada na perspectiva de fundamentação, e até de "desconstrução", em sentido derridiano, do próprio embasamento das indagações sobre a ética do fim da vida. Deslocar-se-ia, em outros termos, o problema do conceito da morte - a ser supostamente estabelecido pela ciência - para um pergunta sobre o exercício da autonomia do próprio interessado, calcado na decisão de não permane- 
cer em um sofrimento indesejável - em um martírio que não o conduzirá a lugar algum (Kottow, 2000) - ou, então, de continuar padecendo, não por uma decisão tomada por outrem, mas, sim, por uma opção pessoal, que pode até ser a de se submeter, por boas razões, à imposição do outro. Nesse sentido, é interessante pontuar que Michel de Montaigne chamou atenção para o fato de que a própria pergunta sobre o problema da morte constitui-se em um ato de liberdade: Meditar sobre a morte é meditar sobre a liberdade; quem aprendeu a morrer, desaprendeu de servir; nenhum mal atingirá quem na existência compreendeu que a privação da vida não é um mal; saber morrer nos exime de toda a sujeição e constrangimento (Montaigne, 2000).

Assim, do ponto de vista da moralidade da eutanásia, não se trata mais de interrogar sobre a morte como fato - quiçá sobre o processo de morrer (ao menos com pretensões “objetivas") -, mas, sim, pela autonomia do homem para decidir por sua liberdade de escolher o próprio fim, ou não. Procurou-se argumentar sobre esta que é a questão principal, tanto para a filosofia moral - inclusa a bioética - como também para a vida que se pensa, e decide, na pessoa autêntica, de ser-para-a-vida-e-para-amorte.

\section{Considerações finais}

As presentes reflexões pleitearam delinear o alcance e os limites do conceito de morte, na medida em que este é pretendido como esteio precípuo ao debate bioético sobre a eutanásia. Nesta desconstrução, tornou-se clara a insuficiência, até hoje, do formulado sobre o assunto, o que levou à tentativa de estabelecimento de uma alternativa - a idéia de autonomia -, a qual foi considerada capaz de contemplar uma série de aspectos fundamentais em relação à eticidade - ou não - da eutanásia. Entretanto, este último conceito apresenta também uma série de problemas, os quais inviabilizariam seu uso de forma irrestrita. Diferentes autores (Kottow, 2000; Schramm, 1998; Segre et al., 1998) pontuam os limites do próprio conceito de autonomia, a saber:

1) a possibilidade, sempre real, de que haja dificuldade para a compreensão de aspectos da realidade representa um genuíno "empecilho" para o pleno exercício da autonomia, sobretudo se é colocado em foco um país - como o
Brasil - no qual a maior parte da população não tem acesso à educação - e formação, no melhor sentido grego da palavra (Jaeger, 1995; Siqueira-Batista, 2003) - necessárias ao exercício da cidadania e do livre direito de optar pelas melhores alternativas para a sua própria existência;

2) a impossibilidade de se constituir um nomos particular - próprio - a partir do nada, uma vez que a tomada de decisões só é levada a cabo no âmbito de coordenadas socialmente determinadas - a liberdade irrestrita é uma ilusão, haja vista todo o "enredamento" cultural no qual o homem se encontra imerso;

3) a possibilidade, à luz da bioética principialista - calcada nos princípios de autonomia, justiça, beneficiência e não-maleficiência, ou outros - de que sempre é factível a existência de conflitos entre os princípios em pauta, reduzindo-se, mutuamente, a congruência de uns aos outros, o que é particularmente observado nas situações em que se priorize a autonomia - neste caso, muitas vezes, se tornaria inviável a aplicação dos demais, quando estes podem, por boas razões, terem uma prioridade léxica (por exemplo, autonomia versus justiça);

4) a existência de uma assimetria nas relações entre profissionais de saúde e pacientes, que pode, em inúmeras oportunidades, tornar inviável a aplicação do princípio - é mencionável, a título de exemplo, a possibilidade de choque entre a autonomia do enfermo e a responsabilidade profissional, como nos paradigmáticos casos em que é indicada hemotransfusão para os Testemunhas de Jeová, em circunstâncias de risco iminente de vida.

Estas brevíssimas ponderações são apenas alguns pontos capazes de explicitar as agudas indagações abordadas pelo exercício da autonomia pessoal diante da relevante questão do binômio vida e morte. Sem embargo, a despeito disto, não se pode abrir mão da idéia de que o titular da própria vida é detentor da prerrogativa de decidir, em condições ótimas - isto é, pressupondo um sujeito, em princípio, cognitivamente e moralmente competente -, sobre seu próprio caminho até a morte. Exatamente aqui está um dos "quês" do problema: propiciar o contexto favorável à liberdade do homem (no sentido de seu "empoderamento" de fato) -, disposição, esta, que possui antigas raízes no Iluminismo, e quiçá, ainda mais arcaicas, no Helenismo. Talvez este seja um dos grandes desafios a serem enfrentados, no futuro, pelo Übermensch - o 'Sobre-homem' nietzschiano - 
o qual, de acordo com uma interpretação "pósmoderna" de Gianni Vattimo, deve ser entendido, sobretudo, como alguém que tenta ir para além de seus limites pessoais, e não como aquele capaz de exercer o poder sobre os demais (Vattimo, 1981).

Todos os matizes, presentemente trabalhados, permitem uma composição na qual o conceito de morte - em sua vertente científica - e o conceito de autonomia - em sua vertente filosófica -, apesar de utilizados como fulcros para o debate ético sobre o fim da vida, albergam dificuldades intrínsecas difíceis de se contornar. Este panorama convida à reflexão, com vistas à busca de novo(s) modelo(s) para a discussão de um aspecto tão inerente à vida, a morte, $\mathrm{o}$ último ato no palco da existência. Nesta interseção criativa consubstancia-se a bioética - forma de ética aplicada que se preocupa, essencialmente, com as possibilidades de compor análise e práxis na tentativa de resolver, da maneira mais imparcial possível, os conflitos e as controvérsias que surgem nas inter-relações humanas -, a qual se vê instada a se debruçar e se redebruçar sobre os possíveis resultados das tentativas de soluções razoáveis, referentes às questões existenciais, de ser-para-a-morte-epara-a-vida, almejando que sejam respeitadas as múltiplas interfaces da vivência humana "à beira de uma eternidade" que pode corresponder, muito bem, à aniquilação e à perdição para sempre.

\section{Referências bibliográficas}

Cedrola JPV, Carvalho GA, Bezerra TS, Siqueira-Batista R \& Siqueira-Batista R 2003. Asclépio, mito e medicina. Revista da Faculdade de Medicina de Teresópolis 5(supl):47.

Coimbra CG 2000. Morte cerebral: falhas nos critérios diagnósticos. Ciência Hoje 27(161):26-33.

Detienne M 1988. Os mestres da verdade na Grécia arcaica. Jorge Zahar Ed., Rio de Janeiro.

Elias N 2001. A solidão dos moribundos. Jorge Zahar Ed., Rio de Janeiro.

França GV 2001. Direito médico. (7ạ ed). Fundo Editorial Byk, São Paulo.

Freud S 1974. Nossa atitude para com a morte. In Obras psicológicas completas de Sigmund Freud, volume XIV. Ed. Imago, Rio de Janeiro.

Gogliano D 1998. Pacientes terminais - morte encefálica. Bioética (Conselho Federal de Medicina). Disponível em <www.cfm.org.br/revista/bio2v1/pacienterm.html>

Grimal P 1997. Dicionário de Mitologia Grega e Romana. (3a ed). Ed. Bertrand Brasil, Rio de Janeiro.

Hegel GWF 1992. A fenomenologia do espírito. Ed. Vozes, Petrópolis.

Heidegger M 1989. Ser e tempo. Ed. Vozes, Petrópolis.

Horta MP 1999. Eutanásia - problemas éticos da morte e do morrer. Bioética (Conselho Federal de Medicina). Disponível em < www.cfm.org.br/revista/biolv7/bio eutanasia.htm $>$

Jaeger W 1995. Paidéia: a formação do homem grego. Tradução de Artur M. Parreira. (3a ed). Ed. Martins Fontes, São Paulo.
Jaspers K 1973. Filosofia da existência. Ed. Imago, Rio de Janeiro.

Jiménez de Asúa L 1942. Libertad para amar y derecho de morir. Losada, Buenos Aires.

Kastembaum RJ 1981. Death, society and human experience. (2a ed). Mosby, St. Louis.

Kipper D 1999. O problema das decisões médicas envolvendo o fim da vida e propostas para a nossa realidade. Bioética 7(1):59-70.

Kirk GS, Raven JE \& Schofield M 1994. Os filósofos présocráticos: história crítica com seleção de textos. Fundação Calouste Gulbenkian, Lisboa.

Kottow M 2000. Enseñando las paradojas de la autonomía. Revista Brasileira de Educação Médica 24 (3):40-45.

Lepargneur H 1999. Bioética da eutanásia: argumentos éticos em torno da eutanásia. Bioética 7(1):41-48.

Luce JV 1994. Curso de filosofia grega: do séc. VI a.C. ao séc. III d.C. Jorge Zahar Ed., Rio de Janeiro.

Machado MH 1997. Os médicos no Brasil. Um retrato da realidade. Fiocruz, Rio de Janeiro.

Martin LM 1998. Eutanásia e distanásia, pp 171-192. In SIF Costa, G Oselka \& V Garrafa (orgs.). Iniciação à bioética. Conselho Federal de Medicina, Brasília.

Menna Barreto SS 2001. Rotinas em terapia intensiva. (3a ed). Artmed Ed., Porto Alegre.

Montaigne M 2000. De como filosofar é aprender a morrer. Ensaios, volume 1. Ed. Abril Cultural, São Paulo.

Neukamp F 1937. Zum Problem der Euthanasie. Der Gerichtssaal, 109:403. 
Palacios MP 1993. Trabalho hospitalar e saúde mental: o caso de um hospital geral e público do município do Rio de Janeiro. Dissertação de mestrado. Instituto de Medicina Social, Universidade do Estado do Rio de Janeiro, Rio de Janeiro.

Pessini L 2001. Distanásia. Até quando prolongar a vida? São Camilo-Loyola, São Paulo.

Rodrigues JC 1983. Tabu da morte. Ed. Achiamé, Rio de Janeiro.

Sartre J-P 1997. O ser e o nada. Ensaio de fenomenologia ontológica. (2a ed). Ed. Vozes, Petrópolis.

Schramm FM 1998. A autonomia difícil. Bioética 6(1):2737.

Schramm FM 1999. Caso clínico (comentário). Bioética (Conselho Federal de Medicina). Disponível em <www.cfm.org.br/revista/bio2v6/casoclinico.htm>

Schramm FR 2001. Por qué la definición de muerte no sirve para legitimar moralmente la eutanasia y el suicidio asistido? Perspectivas Bioéticas 6(11):43-54.

Schramm FR 2002a. Morte e finitude em nossa sociedade: implicações no ensino dos cuidados paliativos. Revista Brasileira de Cancerologia 48(1):17-20.

Schramm FR 2002b. A questão da definição da morte na eutanásia e no suicídio assistido. O Mundo da Saúde 26(1):178-183.

Segre M, Leopoldo e Silva F \& Schramm FM 1998. O contexto histórico, semântico e filosófico do princípio de autonomia. Bioética 6(1):15-26.
Singer P 1998. Ética prática. (2ạ ed). Ed. Martins Fontes, São Paulo.

Siqueira-Batista R 2001. O médico diante da morte: perspectivas de discussão ética com base na filosofia de Immanuel Kant. Revista da Faculdade de Medicina de Teresópolis 3(1):18-22.

Siqueira-Batista R 2003. Deuses e homens. Mito, filosofia e medicina na Grécia antiga. Landy, São Paulo.

Siqueira-Batista R \& Siqueira-Batista R 2002. De como filosofar é aprender a morrer. O pensamento de Michel de Montaigne como pressuposto na discussão sobre a morte e o processo de morrer na prática médica. Cadernos de Saúde Coletiva 10(1):9-18.

Suetônio 2002. A vida dos doze Césares. Tradução de Sady-Garibaldi. (2a ed). Prestígio Ed., São Paulo.

Van der Heide A 1997. Medical end-of-life decisions made for neonates and infants in the Netherlands. Lancet 350(6):251-255.

Vattimo G 1981. Al di là del Soggeto. Nietzsche, Heidegger e l'Ermeneutica. Feltrinelli, Milão.

Weber M1973. Die protestantische Ethik und der Geist des Kapitalismus. Gesammelte Aufsätze zur Religionsoziologie. Vol I. Suhrkamp, Frankfurt a/Main.

Artigo apresentado em 1/7/2003

Aprovado em 11/9/2003

Versão final apresentada em 1@/10/2003 